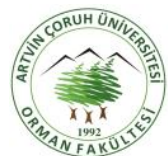

\title{
Uzaktan algılama ve coğrafi bilgi sistemleri yardımıyla Aladağlar’da kış sporları için uygun alanların belirlenmesi
}

\section{Determining the suitable areas for winter sports by using remote sensing and geographical information systems in Aladağ Region}

Anıl AKIN ${ }^{1}$, Mehmet Akif ERDOĞAN²

${ }^{1}$ Bursa Teknik Üniversitesi, Doğa Bilimleri Mimarlık Mühendislik Fakültesi, Şehir ve Bölge Planlama Bölümü, Bursa

${ }^{2}$ Çukurova Üniversitesi, Teknik Bilimler Meslek Yüksek Okulu, Mimarlık ve Şehir Planlama Bölümü, Bursa

\section{Eser Bilgisi / Article Info}

Araştırma makalesi / Research article DOI: 10.17474/artvinofd.305261

Sorumlu yazar / Corresponding author Anıl AKIN

e-mail: anil.tanriover@btu.edu.tr

ORCID: 0000-0001-5267-9105

Geliş tarihi / Received

10.04.2017

Düzeltme tarihi / Received in revised form

17.09.2017

Elektronik erişim / Online available

18.10.2017

\section{Anahtar kelimeler:}

Kayak uygunluk

Çok kriterli analizler

Kış sporları

Keywords:

Ski suitability

Multi criteria analysis

Winter sports

\begin{abstract}
Özet
Çalışmanın amacı, Çukurova bölgesinde ikinci konut ve yayla turizmine doğal bir alternatif olarak Toros Dağları'nın Aladağlar bölgesinde kış sporlarına uygun alanların, uzaktan algılama ve Coğrafi Bilgi Sistemleri (CBS) yardımıyla tespit edilmesidir. Uygun alanların tespiti kar örtüsü, mevcut arazi örtüsü, Sayısal Yükseklik Modeli (SYM) ve buna bağlı verilerden (yükseklik, bakı, eğim grupları, eğim uzunluğu) kullanılarak gerçekleştirilmiştir. Bu kapsamda Landsat TM/ETM ve ASTER uydu görüntüleri uzaktan algılanmış veri seti olarak kullanılmıştır. Çok Kriterli Analizler (ÇKA) yöntemi kullanılarak CBS ortamında çakıştırma ve ağırlıklandırma analizleri gerçekleştirilmiştir. Böylece kayak için uygun alanların belirlenmesinde birden çok değişken ile farklı alternatifler oluşturulmuştur. İlk olarak alan için uygun olan fiziksel çevre koşulları ve giriş verileri saptanmıştır. Bu bilgiler dikkate alınarak kriterler ve kısıtlayıcı faktörler tespit edilmiştir. Kriterler standardize edilerek, yeni başlayanlar, orta düzey ve iyi düzeyde olan kayakçılar için 3 farklı düzeyde uygunluk haritası oluşturulmuştur.
\end{abstract}

\begin{abstract}
The aim of this research was to determine the suitable areas for winter sports alternatively to summerhouses and flatlands in Çukurova using remote sensing and Geographic Information Systems (GIS) in the Aladağ region of Toros Mountain. Appropriate areas were determined based on the snow cover, current land use pattern, Digital Elevation Model (DEM) and related outputs (altitude, aspect, slope groups and slope length) within a GIS environment. Landsat TM/ETM and ASTER images were utilised using various remote sensing data. Multi Criteria Analysis (MCA) was used to determine the suitable areas. This enabled the multi criteria integration to the planning process. Initially, physical environmental factors and inputs were identified, and then criteria and constraints were identified considering these variables. Three categorical maps including beginners, moderate and advanced skiers were created by standardising the subjected criteria.
\end{abstract}

\section{Giriş}

Günümüzde turizmde gelişmiş düzeye gelen ülkeler turizm çeşitlerini arttırmak, turizm hareketlerinin yıl boyu sürekliliğini sağlamak amacıyla ülkelerindeki dağ ve kış turizm olanaklarını etkin bir şekilde kullanmaktadırlar. Dünya'da kış turizmi konusunda büyük gelişme gösteren Amerika Birleşik Devletleri, Kanada, Orta Avrupa ve Alp dağlık yöresinde bulunan Avusturya, İsviçre, Almanya, İspanya, Fransa, İtalya gibi ülkeler ile Romanya'da önemli kış sporları merkezleri bulunmaktadır.

Ülkemizde ise Cumhuriyet'in kuruluşu ile birlikte dikkat çekmeye başlayan dağ sporları ve gezileri 1936 yılında kurulan Beden Terbiyesi Genel Müdürlügü bünyesinde yer alan "Dağcılık ve Kış Sporları Federasyonu” ile resmi olarak başlamıştır. IIlk olarak Uludağ'da yapılmaya başlayan dağcılık ve kış sporları daha sonra Kayseri, Erzurum, Sarıkamış gibi merkezlerde geliştirilmeye başlanmıştır. 1960-1965 yıllarını kapsayan dönemde Uludağ, Erciyes, Palandöken, Sarıkamış ve Bitlis öncelikli kayak merkezleri kabul edilerek bu merkezlerde kayak mekanik tesisleri kurulmuştur. 1970-1980 yıllarında ise Türkiye'de dağcılık ve kış sporların yanı sıra Dağ Turizmi ve Kış Turizmi gelişmeye başlamıştır. Ancak dağ turizmi dış turizme, kış turizmi ise iç turizme yönelik gelişme göstermiştir.

Ülkemizde mevcut spor ve kış turizmi ağırlıklı olarak kullanılan merkezler özellikle Avrupa ülkelerindeki kış sporları merkezleri ile rekabet edebilecek olanak ve kapasitede olmamakla birlikte yeni açılacak ve açılması 
öngörülen alanlarla ve mevcut alanlarda öngörülen yeni yatırımlarla birlikte gelişme dönemine girmektedir. Türkiye'de bulunan kayak merkezlerinin başında Ağrı-Bubi Dağı, Ankara-Elmadağ, Antalya-Saklıkent, Bingöl-Yolaçtı, Bitlis-Merkez, Bolu-Kartalkaya, Bursa-Uludağ, Elazığ-Sivrice Hazarbaba, Erzincan-Bolkar, Erzurum-Palandöken, Gümüşhane-Zigana, Isparta-Davraz, İzmir-Ödemiş Bozdağ, Kastamonu-Ilgaz, Kars-Sarıkamış, Kayseri-Erciyes yer almaktadır (Anonim 2003).

Dağ ve kış turizmine son derece elverişli yüksek ve orta yükseklikteki dağlar ve ormanlık alanlara sahip olan ülkemizde dış turizme yönelik dağcılık ve dağ turizmi Kültür ve Turizm Bakanlığı tarafından planlanmıştır. Ancak birinci derecede öncelikli olan kış sporları merkezlerimizde bile yanlıs arazi kullanımları, plansız ve çevre ile uyumu olamayan turizm yatırımları bulunmaktadır. Hassas mekanlar olan dağlık alanlarda yapılacak kış turizmi ve kış sporları merkezlerinin planlamasında kayak uygulamalarının türüne ve yapılış kurallarına uygun pistler ile kayakçıları taşıyan kayak mekanik tesisleri ile konaklama amaçlı yer seçiminde kullanım ölçütlerine uyulması gerekmektedir. Bu kapsamda çalışmanın amacı Toros Dağları'nın Aladağlar bölgesinde kış sporlarına uygun alanların uzaktan algılama ve CBS yardımıyla tespit edilmesidir.

\section{MATERYAL ve YÖNTEM}

\section{Çalışma Alanı}

Araştırma alanı, Akdeniz Bölgesi'nde Niğde, Kayseri, Adana illeri sınırları içerisinde yer almaktadır. Toros sıradağlarının en yüksek zirvelerine sahip olan Aladağlar'ın, 54.524 hektarlık bölümü 1995 yılında millipark ilan edilmiştir. Çalışma alanı Şekil 1'de verilmiştir.

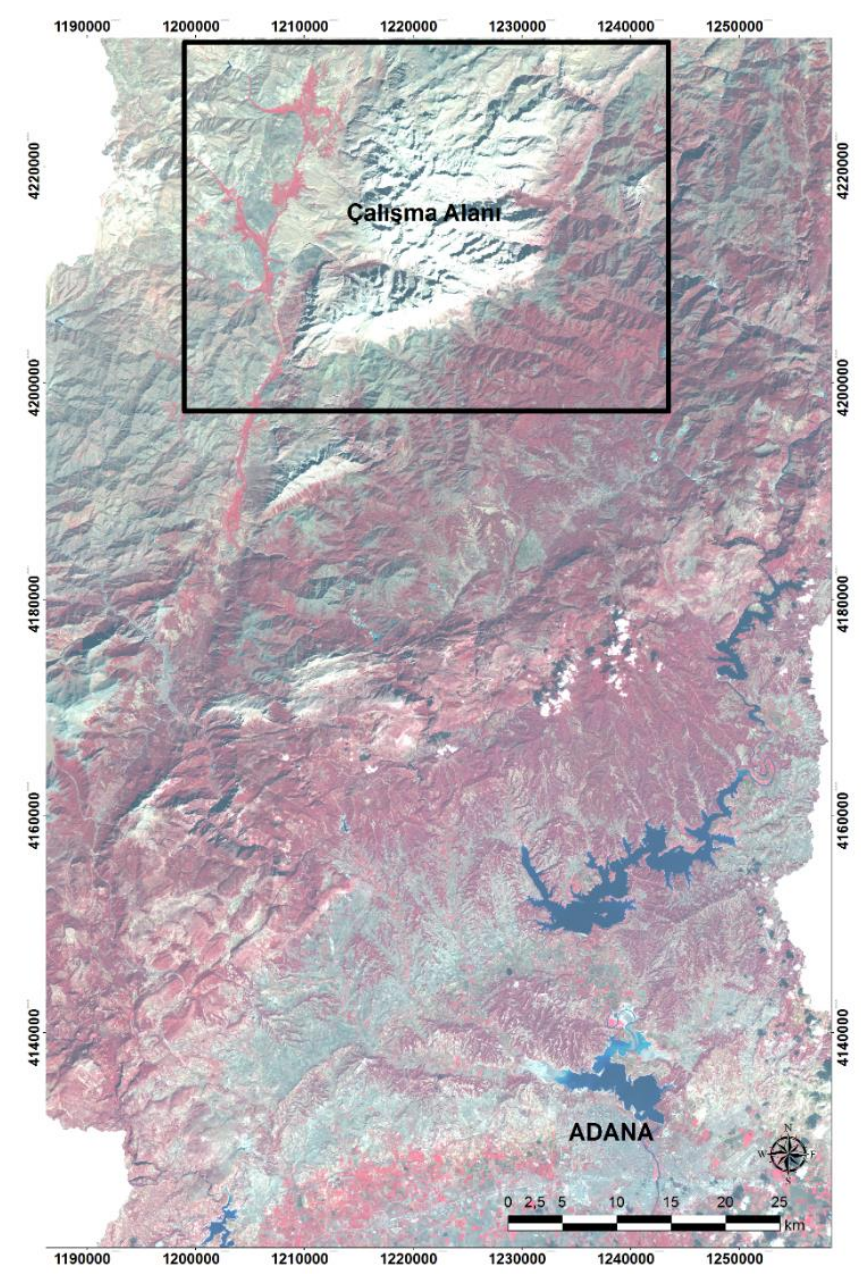

Şekil 1. Çalışma alanının konumu (Landsat, 2015) 
Çalışmanın ana materyalini 2015 yılı Landsat ETM ve güncel ASTER görüntüleri oluşturmaktadır. Alanla ilgili hidrolojik verilere Adana Devlet Su İşleri Bölge Müdürlüğü'nün bölgede yaptığı çalışmalardan ve iklimsel verilere alan içinde ve çevresinde yer alan 11 adet meteorolojik istasyondan ulaşılmıştır. Ayrıca bölgeye ilişkin topoğrafik haritalardan yararlanılmıştır. íklim verileri, kar örtüsü dönemlerinin belirlenmesinde kullanılmış, uydu görüntüleri bu zaman periyotlarında seçilmiştir.

Uygun alanların tespiti kar örtüsü, mevcut arazi örtüsü, SYM ve buna bağlı verilerden üretilmiş yükseklik, bakı, eğim grupları ve eğim formu kullanılarak CBS ortamında gerçekleştirilmiştir. Arazi örtüsü sınıflamasında Landsat ve ASTER verilerinden yararlanılmıştır. illk olarak, farklı mevsimlerde kaydedilmiş olan 5 adet Landsat görüntüsünden yararlanılarak mevsimsel kar örtü alanları tespit edilmiştir. Sonrasında $15 \mathrm{~m}$ yersel çözünürlüğü ve görülebilir bölgede üç, yakın kızılötesinde bir bandı olan ASTER görüntüsü mevcut arazi örtüsünün ayrıntılı olarak haritalanmasında kullanılmıştır. Her iki görüntü sınıflamasının yüksek doğrulukla yapılabilmesi için geleneksel Maksimum Olabilirlik (Maximum Likelihood) yöntemi kullanılmıştır. Sınıflama doğruluğunu artırmak amacıyla görüntülerin yansıma bantlarının yanı sıra görüntü tekstür bantları üretilerek sınıflamaya dahil edilmiştir. Tekstür hesaplamaları Geo-istatistiksel yöntemlerden variogram çalışma amacı doğrultusunda geliştirilmiş GSLIB yazııımı ile üretilmiştir. Tekstür haritası, arazi örtüsünün yüksek doğrulukla haritalanmasında yardımcı olmuştur. Çalışmanın genel akış diyagramı Şekil 2'de verilmiştir.

\section{Çok Kriterli Analizler}

Çalışmada, belirlenen değişkenler ÇKA yöntemi kullanılarak çakıştırılmış ve ağırlıklandırılmıştır. Çok kriterli analizlerin temel amacı, olası çözümlerin karşılaştırılmasında bir belirleyici olarak, karar verme sürecinde çoklu kriterlerin entegrasyonunun sağlanmasıdır. Kaynak gelişimi için alanın konumuyla ilgili karar verme aşaması en önemli gereklerden biridir. CBS'nin gelişmesiyle birlikte alan kullanımı ile bilgileri daha geniş ve kapsamlı değerlendirme şansı doğmaktadır ve farklı alternatiflerin oluşturulmasına katkıda bulunmaktadir (Eastman ve ark. 2005).

Çok kriterli analizlerde önemli noktalardan biri çalışma alanına ait faktörlerin ve kısıtlayıcıların (limitlerin) belirlenmesidir (Carver 1991). Faktörler ve kısıtlayıcılar; alana özgü alternatiflerin uygunluğunu azaltan veya arttıran kriterlerdir. Bu kriterler hedeflenen aktivitelere bağlı olarak belirlenmektedir. Kısıtlayıcılar, düşünülen alternatiflerin sınırlarını göstermektedir. Faktörler ise planlama kararlarının değerine göre uygunluğu etkileyen kriterlerdir. Her bir kriter önem derecesine göre değerlendirilmektedir (Beinat ve Nijkamp 1998).

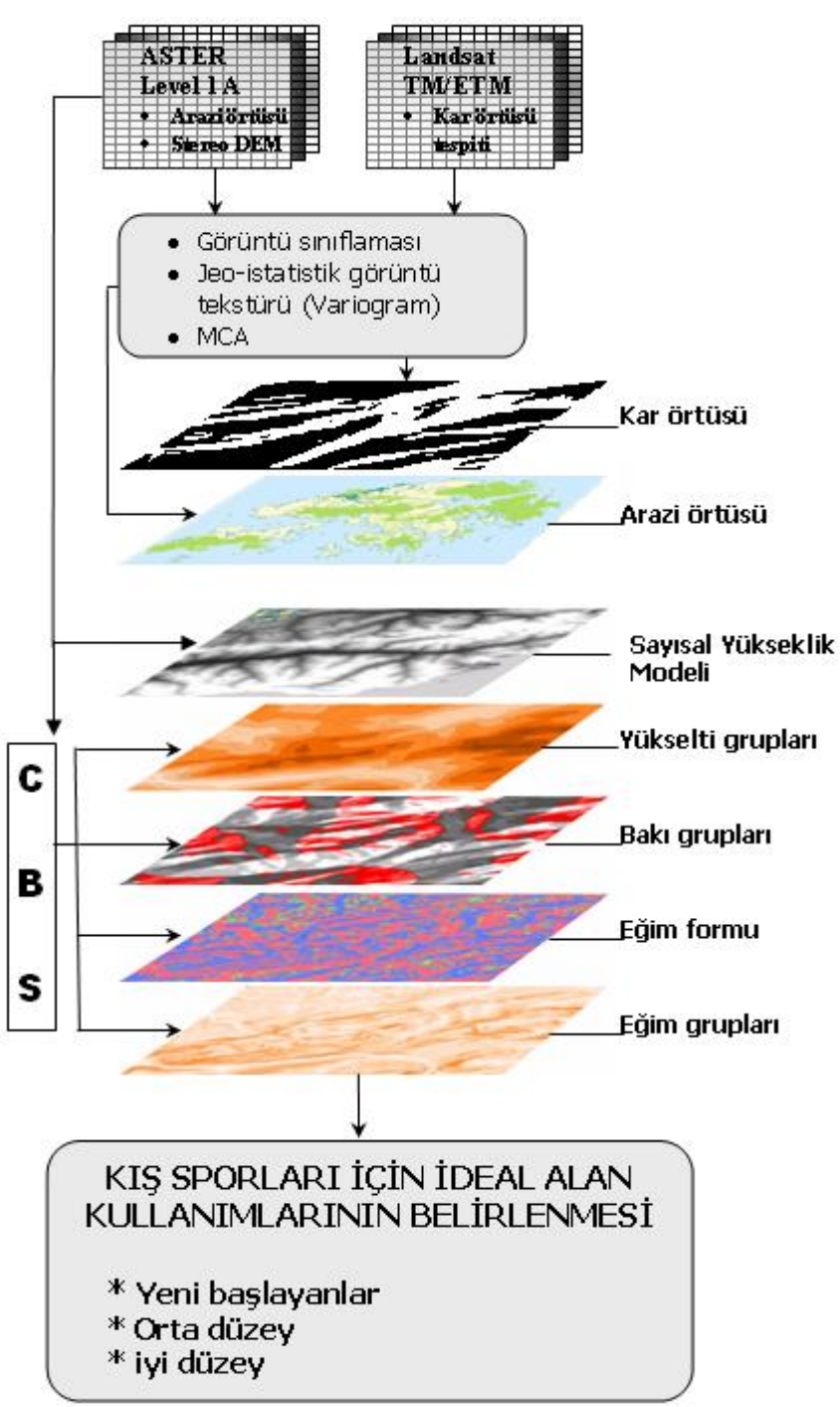

Şekil 2. Genel akış şeması. 
Çalışmanın bu çerçevedeki genel akış şeması Şekil 3'de verilmektedir. Bu şemada ÇKA'de kullanılacak olan çevresel girdiler ve elde edilen çıkış verileri görülmektedir.

\section{Tekstür}

Birbirine yakın olan noktalar arasındaki ilişki, birbirine uzak olan noktalara göre daha yüksektir. Bu benzerlik ve farklııklar çevreye ve gözlem şekline bağlı olarak değişmektedir. Görüntü tekstürünün iki farklı hedefi bulunmaktadır: (i) görüntüdeki piksellerin değişkenliğinin saptanması; (ii) pikseller arasındaki ilginin bu değişkenliğe bağlı olarak tanımlanmasıdır (Janssen 1992). Görüntü tekstürü üretimi basit ikinci derece istatistik hesaplamalarla (örneğin; varyans, standart sapma) olabildiği gibi daha ileri derece istatistikler örneğin, tekrar oluşum matrisleri kullanılarak da hesaplanabilir. Bunların yanı sıra son yıllarda uzaktan algılamada kullanılmaya başlayan geo-istatistiksel tekstür hesaplamaları klasik yöntemlere göre daha fazla bilgi sağlamaktadır (Carr 1996).

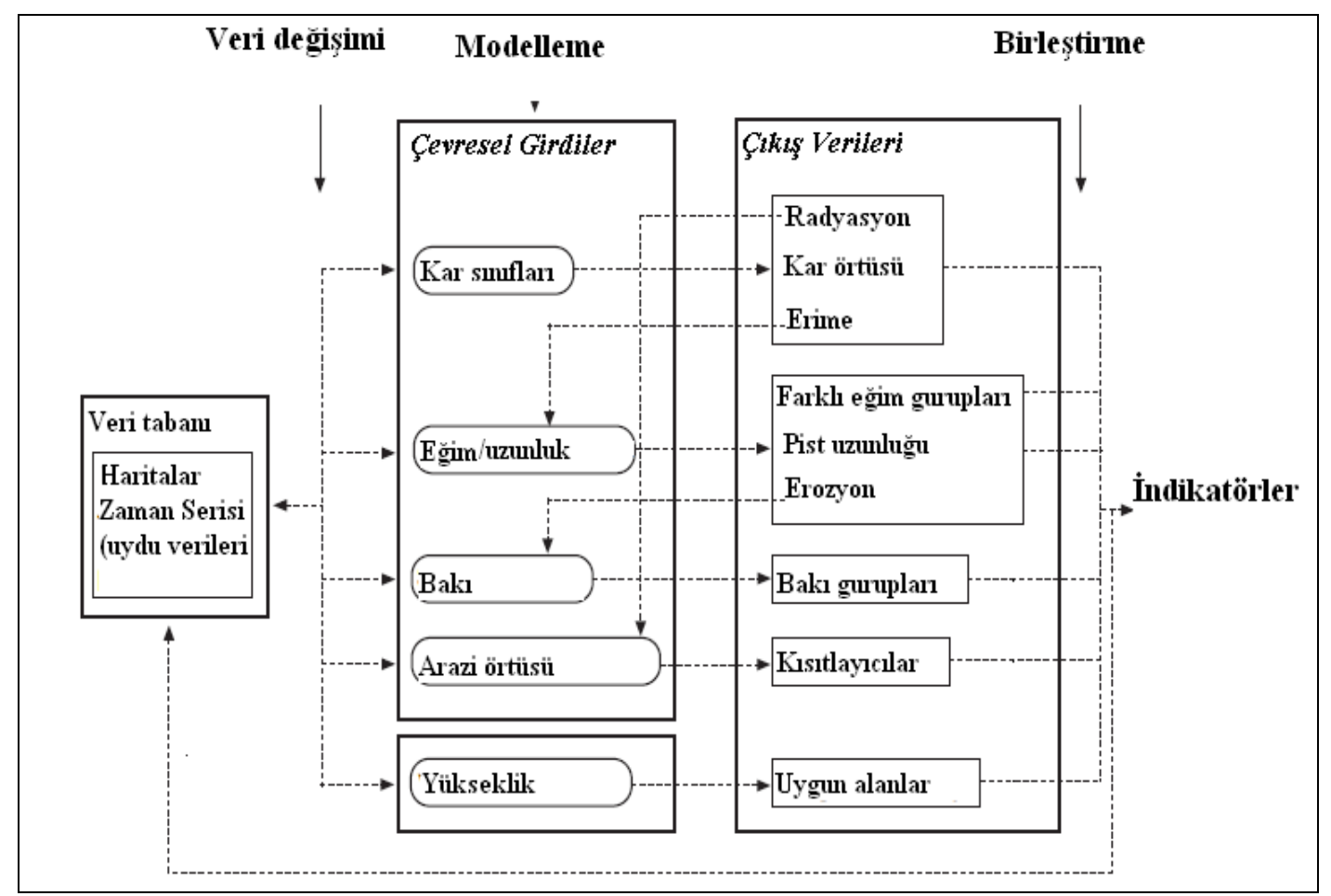

Şekil 3. Çok kriterli analizi (MCA) yönteminin genel akış şeması

Çalışmada geo-istatiksel yöntemlerden biri olan Kriging yöntemi örnek veri üzerinden toplam kayak alanları için yükseklik verisini interpole etmede kullanılmıştır. Variogram modelinden eşik (sill), parça (nugget), aralık (range) ve mesafe (lag) değerleri elde edilmiş daha sonra bu değerler GBS ortamında en doğru kriging sonuçlarını oluşturmak için kullanıımıştır. Parça $c_{0}$ modelin y aksını kestiği noktadır. Aralık (a) semivaryansın üst limite ulaştığı ilk noktadır ve $x$ ekseninde mesafe ( $h$ )' $ı n$ bu noktaya gelen karşıı̆ı̆yla ifade edilir, y eksenindeki karşılığı ise eşik değeri ile ifade edilir (Şekil 4). Aralık ve eşik değerleri bir variogramın en önemli iki parametresidir. Aralık bir görüntüdeki tekstürün homojenliği (kaba veya ince tekstür) ve görüntüdeki objelerin büyüklüğü, eşik değeri ise objelerin bir alanı kapsama oranları ilgili bilgi verir (Miranda ve ark. 1992). Variogramdan elde edilen bu farklı tekstür bilgileri yansıma karakterleri benzerlik gösteren arazi örtüsü sınıflarının ayrımını kolaylaştırmıştır (Berberoğlu 1999). Arazi örtüsü sınıflamasında, Geoistatistiksel analizlerden diğeri olan tekstür, sınıflama doğruluğunu artırmak için çalışmaya entegre edilmiştir.

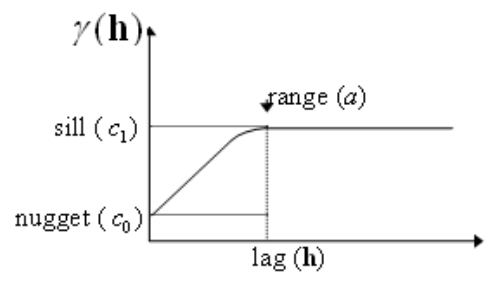

Şekil 4. Matemetiksel olarak modellenmiş variogram 


\section{BULGULAR}

Illk olarak çalışmada kullanılan yersel değişkenler ortak bir ölçeğe (0-1 arası) getirilmiştir. Standardizasyon olarak tanımlanan bu işlemde Fuzzy yaklaşımı kullanılmıştır. Fuzzy yaklaşımda her bir Fuzzy seti fonksiyonu değerlendirilerek bu setlere ait her bir piksel için değerlendirme yapılır. Sigmoidal, J-shaped ve doğrusal fonksiyonlar değer ölçeğindeki en yüksek ve en düşük değerlerden elde edilen kontrol noktaları ile biçimlendirilir. İlk nokta fonksiyonun sıfırdan yükselmeye başladığı alanı temsil etmektedir. íkinci nokta fonksiyonun 1'e ulaştığı yerdir. Üçüncü nokta fonksiyonun yeniden 1 den aşağı doğru düşmeye başladığı alan ve 4 . nokta ise fonksiyonun 0 değerine geri döndüğü alandır (Eastman ve ark. 2005). Şekil 5'de Fuzzy fonksiyonun ihtiyaç duyduğu 4 adet kontrol noktasına ait değerler verilmiştir. Fuzzy yöntemi ile kriterler arasında belirlenen farklı sınırların birbirleri içindeki ve arasındaki geçişleri de yumuşatılmıştır.

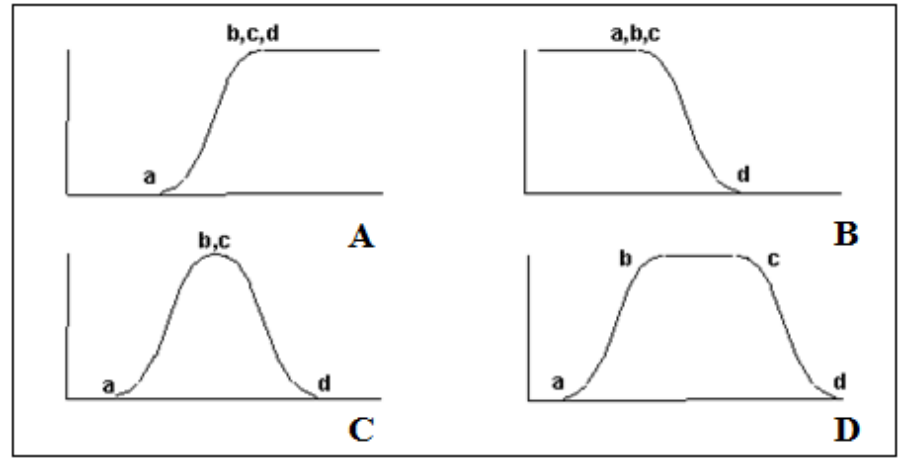

Şekil 5. Sigmoidal fonksiyonlar (A) monoton olarak artan, (B) monoton olarak azalan, (C) ve (D) simetrik

Çalışmada belirlenen giriş verileri ve bu verilere göre oluşturulan kriterler ise aşağıda belirtilmiştir (Çizelge 1 , Şekil 6).

Çalışmada yeni başlayanlar, orta ve iyi derece kayakçılar için üç ayrı uygunluk alanı oluşturulmuştur ve ayrı ayrı kodlanarak analizlere dahil edilmiştir. Farklı alternatiflerin değerlendirilmesinde kullanılan bazı standartlar Çizelge 2'de verilmektedir (Anonim 2003).

Çizelge 1. Yersel Değişkenler ve Tanımları

\begin{tabular}{|c|c|}
\hline Yersel Değişkenler & Tanım \\
\hline Aster Uydu Verisi & Mevcut arazi örtüsü üretiminde kullanılmıştır. \\
\hline SYM & Stereo EOSAT-ASTER Level 1A görüntüsünden 15 m çözünürlüğünde SYM üretilmiştir. \\
\hline Yükselti grupları: & $\begin{array}{l}\text { Çalışma alanı yükseklik değerleri } 484 \mathrm{~m} \text {. ile } 3606 \mathrm{~m} \text {. arasında değişmektedir. Bu yükseklikler yaklaşık } 412 \mathrm{~m} \text {. olmak üzere } \\
\text { eşit aralıklarla toplam } 10 \text { gruba ayrılş̧ır. }\end{array}$ \\
\hline Bakı Grupları: & $\begin{array}{l}\text { SYM kullanılarak } 360^{\circ} \text { lik açı ile topografik yapının bakıları belirlenmiştir. Elde edilen harita kış sporlarında gerekli olan } \\
\text { kriterler arasında yer alana kar örtüsünün kalma süresi ve miktarı nedeniyle önem taşımaktadır. }\end{array}$ \\
\hline Eğim Grupları & $\begin{array}{l}\text { Eğim grupları SYM kullanılarak derece olarak belirlenmiştir. Alanın eğimi 0-25 derece arasında yoğunlaşmıştır. Eğim } \\
\text { gruplarına ek olarak eğim uzunluğuna ait bilgide üretilmiştir. Buna göre } 2432 \mathrm{~m} \text {. optimum uzunluk olarak tanımlanmıştır. }\end{array}$ \\
\hline AÖ/AK sınıflaması & $\begin{array}{l}\text { Aster görüntüsü Maksimum Olabilirlik yöntemleri kullanılarak eğitimli sınıflanmıştır. SYM ve 1:25.000 ölçekli Orman } \\
\text { Meşcere haritaları doğruluğu artırmak amacıyla sınıflamaya dahil edilmiştir. }\end{array}$ \\
\hline Kar Örtüsü Sınıflaması & $\begin{array}{l}\text { Kış aylarına ait Landsat arşiv görüntüleri kullanılarak kar örtüsü yayılımının farklı mevsimlerdeki dağılımı tespit edilmiştir. } \\
\text { Elde edilen sınıflama görüntüsünden kar bilgisi maskelenmiştir. }\end{array}$ \\
\hline
\end{tabular}




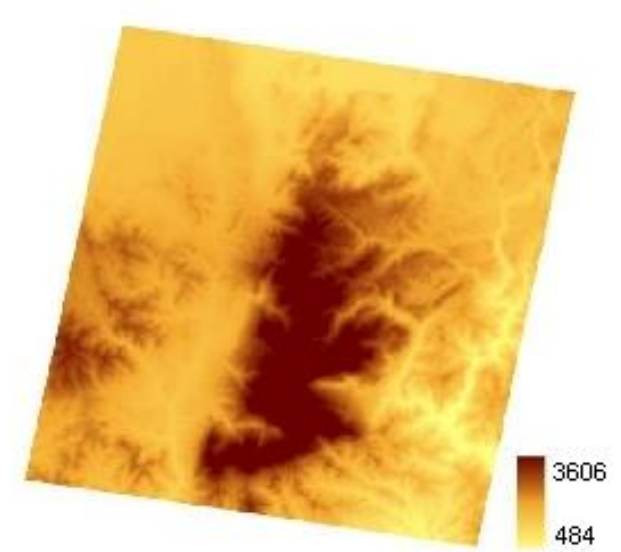

Sayısal Yükseklik Modeli

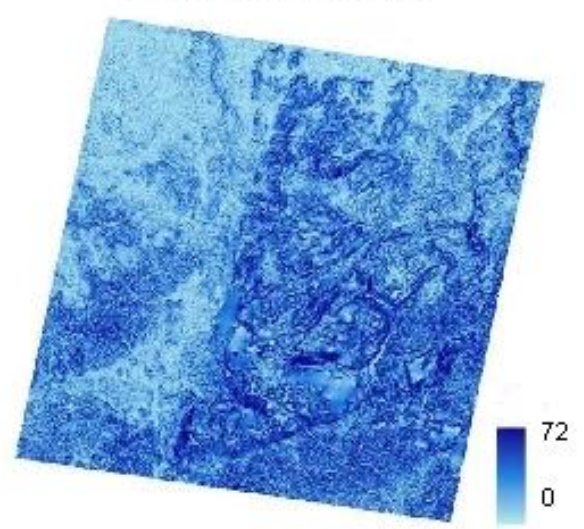

Eğim Haritası (Derece)

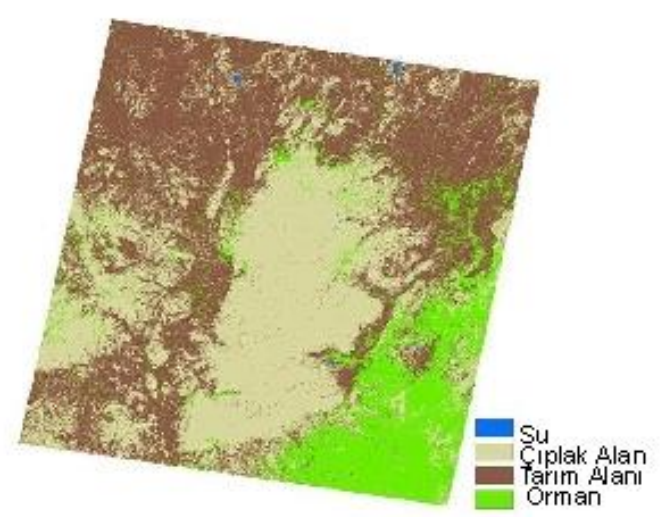

Arazi Sınıfları Haritası

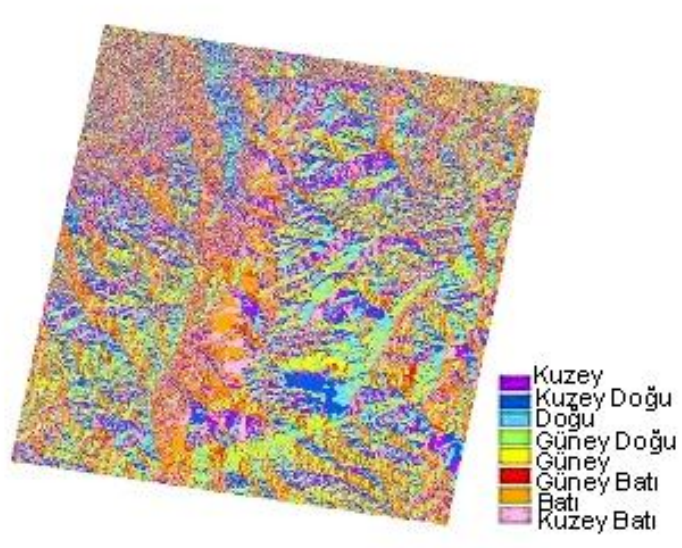

Bakı Haritası

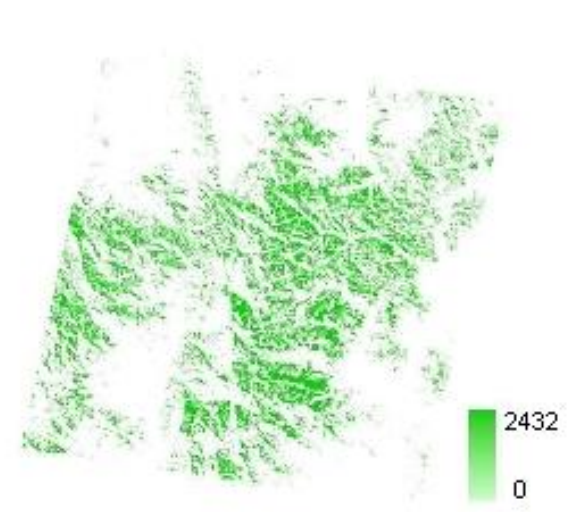

Eğim Uzunluğu Haritası (m)

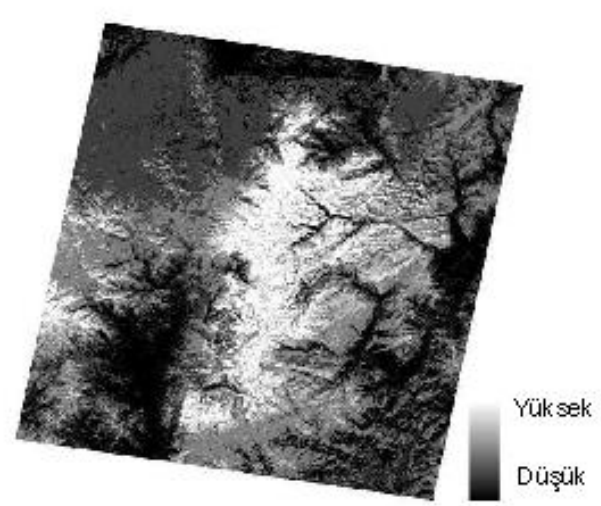

Kar Kalıcılık Haritası

Şekil 6. Kayak alanları tespitinde kullanılan girdi verileri

Çizelge 2. Kayakçılar için ortalama standartlar

\begin{tabular}{llll}
\hline & Yeni Başlayan Kayakçılar & Orta Derece Kayakçılar & İyi Düzey Kayakçılar \\
\hline Her bir saat kaymak için dikey iniş & $100-300$ & $500-700$ & $1000-1500$ \\
& $350-1000$ & $1600-2300$ & $3500-5000$ \\
$\begin{array}{l}\text { Genellikle kablolu taşıyıcıların kullanıldı̆̆ı dikey } \\
\text { iniş }\end{array}$ & 300 den az & $300-700$ & 700 den fazla \\
Ortalama yol eğimi & 60 & $15^{0}$ & $25^{\circ}$ \\
\hline
\end{tabular}


Arazi örtüsü/alan kullanım sınıflamasında su, çıplak alan, tarım alanı, orman ve kar olmak üzere 5 genel sınıf belirlenmiş̧ir. Kar örtüsü sınıflaması kış aylarına ait Landsat arşiv görüntüleri kullanılarak tespit edilmiştir. Özellikle kar örtüsünün başladığı Aralık ve azalmaya başladığı Mart görüntüleri (Kasım, Aralık, Ocak, Şubat, Mart) çakıştırılarak kar örtüsünün alanda bulunma ve yayılışı tespit edilmiştir. En az 2 farklı zamanda kar örtüsü bulunan alanlar kar örtüsü yönünden uygun kabul edilmiştir. Landsat görüntüsünün 5 . bandı olan ortakızılötesi bant ile 4. bant olan yakın kızılötesi bandı oranlanarak topoğrafik etki normalize edilerek sınıflamaya dahil edilmiştir. Kayak pistleri için uygun bakı grupları yukarıda belirtilen ilkeler çerçevesinde KuzeyKuzeydoğu-Doğu olarak belirtilmiştir ve eşit öneme sahiptir. Uygun eğim grupları $6^{0}-25^{0}$ eğimler olarak belirlenmiş ve kayakçı yetenek sınıflarına göre (yeni başlayan, orta ve iyi) sınıflanmıştır. Bu sınıflamada $2^{0}-6^{0}$ yeni başlayanlar için, $7^{0}-15^{\circ}$ orta ve $16^{\circ}-25^{0}$ iyi düzeydeki kayakçılara uygun eğimler olarak haritalanmıştır. Diğer bir ifadeyle üç farklı kategori için üç farklı eğim haritası oluşturulmuş ve ayrı ayrı değerlendirmeye alınmıştır. Farklı kategoriler için ait olduğu eğim grubu en yüksek uygunluk değerine sahiptir. Aster uydu görüntüsü ile elde edilen arazi sınıflaması kullanılarak orman alanları ve su yüzeyleri dışında kalan bölgeler (kısıtlayııılar) kayak pisti yapımına uygun olarak kabul edilmiştir.

\section{Standardizasyon ve Ağırlıklandırma}

Faktörler ve kısıtlayıcılar belirlendikten sonra her değerlendirme kriterine bir öncelik değeri atanmıştır. Türkiye ve Dünya çapında kayak alanlarının planlanmasında önemli olan faktörler dikkate alınarak uygunluk indeksi (suitability index, SI) hesaplaması yapılmıştır (Anonim, 2016). Fakat bu teknik kılavuzlarda değişkenlerin öncelik sıralamasına (ağırlıklandırma) ait herhangi bir bilgi yer almamaktadır. Ağırlıkların belirlenmesinde arazi örtüsü/alan kullanım uygunluğu, uzaktan algılama, kayak pisti standartları ve güvenliği konularında uzman 7 kişiden görüş alınmıştır. Uzman grubu Peyzaj Mimarlı̆̆ı, Şehir ve Bölge Planlama, Fizik Bölümü ve İnşaat Mühendisliği disiplinlerinden oluşmaktadır. Uzmanlardan faktörler arasında karşılaştırma yapmaları istenmiş ve sonrasında 1-5 arasında bir puanlama ile katsayılar hesaplanmıştır.
Ayrıca konuyla ilgili çalışmalar dikkate alınmıştır (Düzen ve Şatır, 2016; Dezsi, 2015; Silberman and Rees, 2010). Faktörleri, alanlarının planlanmasındaki önem derecelerine göre kıyaslamak gerekirse ilk sırayı kar örtüsü (KO), ikinci sırayı eğim, üçüncü sırayı bakı (B), dördüncü sırayı eğim uzunluğu (EU) ve son sırayı ise yükseklik (SYM) almaktadır (Çizelge 3). Her bir kriterin ağırlıklandırma katsayı belirlendikten sonra bu katsayı ilgili veri seti değerleri ile çarpılmıştır. Bu işlem sonucunda yeni başlayanlar, orta düzey ve ileri düzey kayıcılar için üç farklı uygunluk haritası oluşturulmuştur.

Çizelge 3. Uygun kayak alanları ağırlıklandırma değerleri

\begin{tabular}{lll}
\hline Uygunluk Değişkeni & Ağırlıklandırma & Tanımı \\
Kar örtüsü (KO) & 4 & En önemli \\
Eğim (E) & 3 & Çok önemli \\
Bakı (B) & 3 & Çok önemli \\
Eğim uzunluğu (EU) & 2 & Önemli \\
Yükseklik (DEM) & 1 & Az önemli \\
\hline Toplam & $\mathbf{1 3}$ & \\
\hline
\end{tabular}

Uygunluk indeksi $(\mathrm{SI})=\left(4 S \mathrm{I}_{\mathrm{KO}}+3 \mathrm{~S} \mathrm{I}_{\mathrm{E}}+3 \mathrm{~S} \mathrm{I}_{\mathrm{B}}+2 \mathrm{SI}_{\mathrm{EU}}+1 S \mathrm{I}_{\mathrm{DEM}}\right) / 13$

$\mathrm{SI}_{\text {Ko: }}$ Kar örtüsü için uygunluk indeksi

$S l_{E}$ : Eğim için uygunluk indeksi

$\mathrm{SI}_{\mathrm{B}}$ : Bakı için uygunluk indeksi

$\mathrm{SI}_{\mathrm{EU}}$ : Eğim uzunluğu için uygunluk indeksi

SI DEM: Yükseklik için uygunluk indeksi

Ağırlıklandırma ve çakıştırma sonucu elde edilen haritalar Şekil 7'de verilmiştir. Üç grup için oluşturulan üç boyutlu arazi modeli ise Şekil 8 ' de verilmektedir.

\section{TARTIŞMA ve SONUÇ}

Kar gelişmemiş ülkelerde bir sorun olarak görülse de gelişmiş ülkelerde bir kaynak olarak kabul edilmektedir. Bu kapsamda kış turizminin planlaması kısmen karmaşık ve kendine özgü bir yapısı ve sorunları olan bir çalışmadır. Doğal güzellikleri, uygun iklim ve coğrafi konumu sayesinde Türkiye'nin gittikçe atan turizm etkinlikleri ekonomisine katkıda bulunmaktadır. Orta ve Doğu Anadolu'da kayak için uzun dönem yetecek kar kapasitesine sahip olan üç dağda yapılabilmektedir (Gürer ve ark. 2004). Buna karşın sahip olunan bu potansiyel hala yeterince değerlendirilememektedir. 
Daha önce yapılan çalışmalar göstermiştir ki kayak alanlarının geliştirilmesinde etkili en önemli faktörler kullanıcı talebi ve ekonomik faydadır. Bu nedenle uygun kayak alanlarını belirlerken ortamın çevresel hassasiyeti ekonomik ve sosyal faktörlerle birlikte mutlaka ele alınmalıdır ve bu faktörler arasında denge oluşturabilecek bir yöntem geliştirilmelidir.

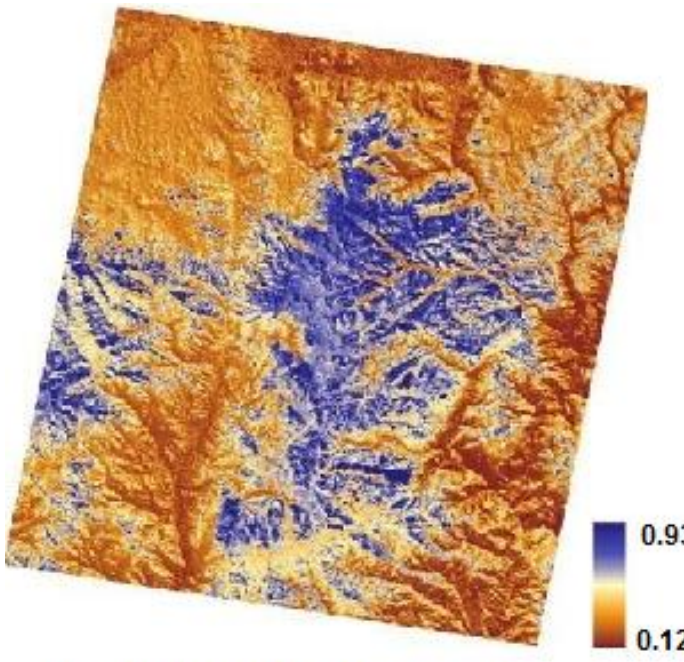

Başlangıç Düzeyi Uygunluk Haritası

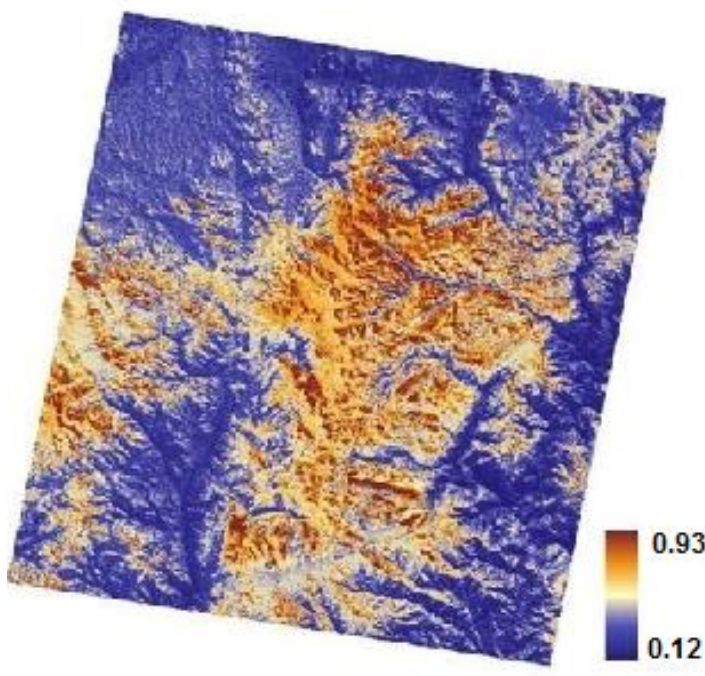

lyi Düzey Uygunluk Haritası

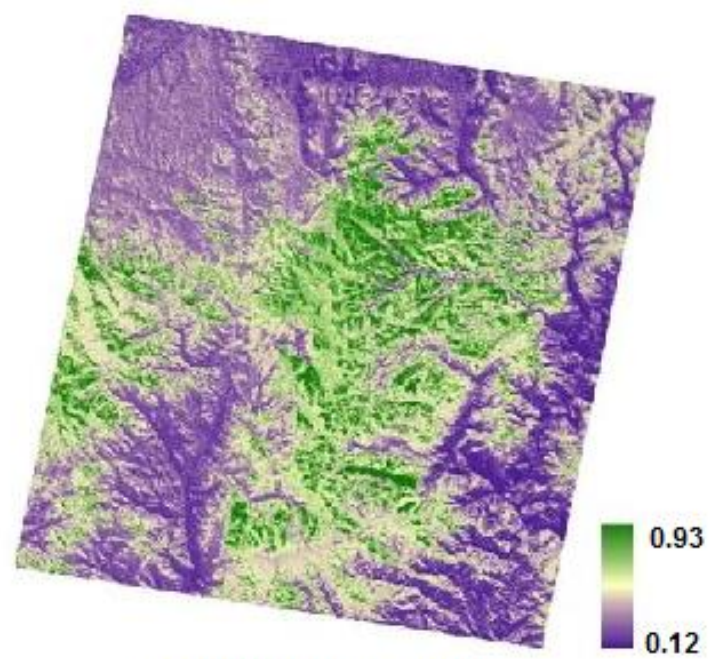

Orta Düzey Uygunluk Haritası

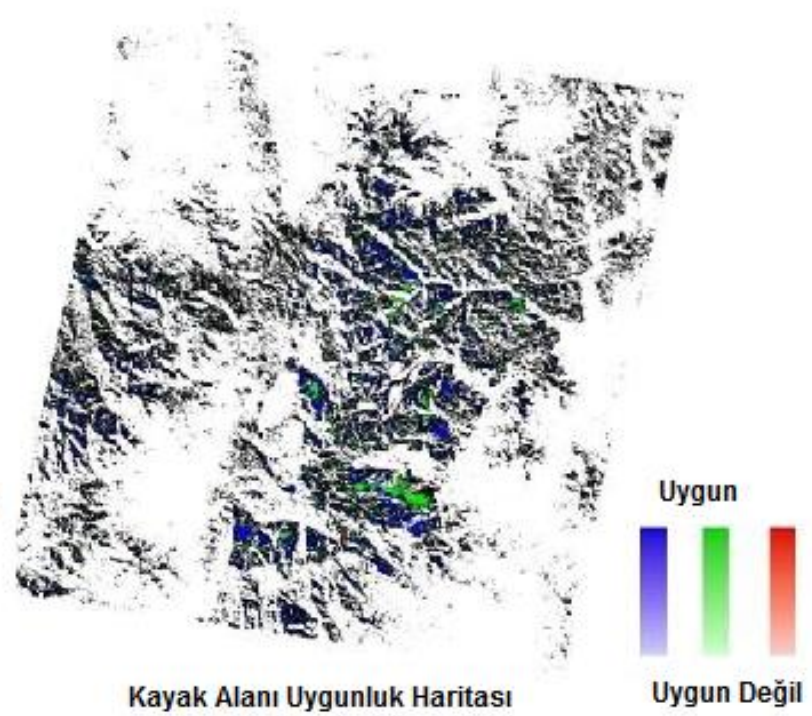

Şekil 7. Farklı gruplar için oluşturulan uygunluk haritaları 


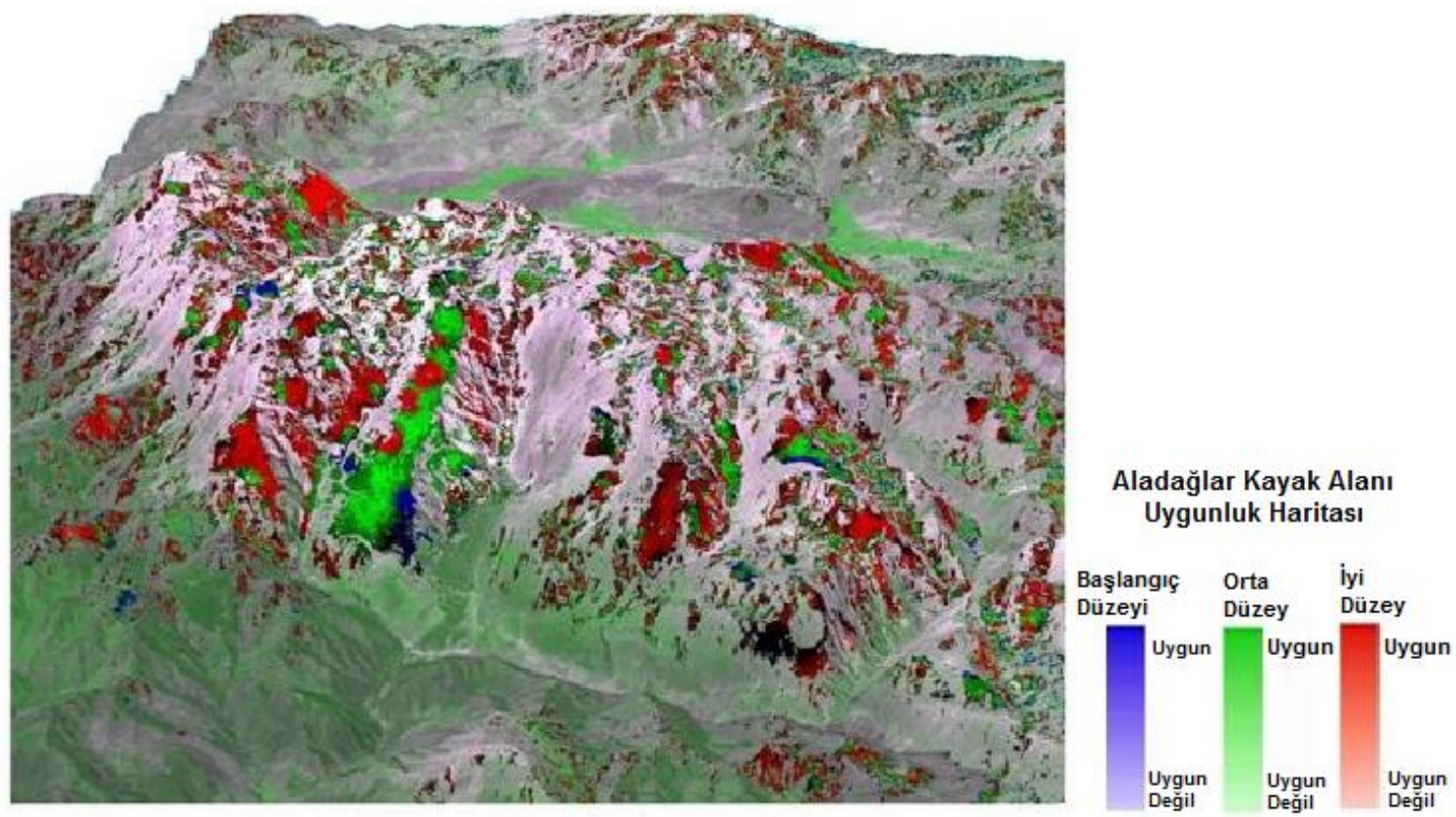

Şekil 8. Aladağlar kayak alanı üç boyutlu uygunluk haritası

Kayak merkezlerinin hizmet kalitesi bakımından değerlendirildiği ya da benzer olarak yerli ziyaretçilerin kış turizmine yönelik seyahat motivasyonlarının (rahatlama, kendini geliştirme, huzur, sosyalleşme), seyahat memnuniyeti alt boyutlarıyla (pist, alışveriş, güvenlik, konaklama, eğitmen, ulaşım) değerlendirildiği çalışmalar mevcuttur (Ayaz ve Apak, 2016; Gençer ve ark, 2008). Fakat bu çalışmalar daha çok kullanıcı memnuniyetine dayanmaktadır. Bununla birlikte günümüzde çevresel hassasiyeti dikkate alan çalışmaların sayısı da artmaktadır. Örneğin, Topay ve Parladır (2014) yaptıkları bir çalışmada, Isparta ili'nde atla gezinti, dağ bisikleti, dağcllık, kamping/çadırlı kamp, kayak ve trekking etkinlikleri için ekolojik, ekonomik ve kültürel açıdan uygun alanları birlikte değerlendirerek bütüncül bir uygunluk analizi yapmıştır. Farklı etkinlikler için uygun alanlar nitel ve nicel olarak belirlenmiştir. Düzen ve Şatır (2016), Van ve Bitlis illeri sınırları içerisinde profesyonel kayakçılar için uygun kayak alanların belirlenmesine yönelik bir çalışma yapmıştır. Kar kapalılı̆̆ı, güneşlenme açısı, eğim uzunluğu, eğim ve yükseklik değişkenleri ÇKA yöntemi kullanılarak değerlendirilmiştir. Söz konusu çalışma fiziksel değişkenler ile yapılmış, değerlendirme aşamasında uzman görüşü alınmıştır.

Çalışmada, Türkiye'deki yoğun kıyı turizmine alternatif olarak kayak turizmi için sayısal bir yöntem geliştirilmiştir.
Farklı veri setlerinin karşılaştırılmasına imkan veren ve dünyada özellikle çevresel uygulamalar başta olmak üzere bir çok karşılaştırmalı analizlerde kullanılan ÇKA Aladağlar kayak alanı uygunluk haritasının oluşturulmasında kullanılmıştır. Orman alanları ve su yüzeyleri, çalışma dışı bırakılmıştır. Bununla birlikte, kullanılan teknikler yardımıyla klasik yöntemlere göre doğruluğu daha yüksek ve kullanıma daha uygun elektronik formatta veri üretilmiştir. Oluşturulan model ülkemiz genelinde kullanılması durumunda kış turizmine uygun ideal alanların belirlenmesi yanı sıra erozyon gibi çok yaygın sorunlar için önlem ve politika üretilmesine yardımcı olacaktır. Uzaktan algılamanın kullanımının devlet sektöründe yaygınlaşıyor olması araştırma sonucu elde edilen modelin kullanılabilirliğini artırmaktadır.

\section{KAYNAKLAR}

Anonim (2003) http://www.kayakturkiye.com/

Anonim (2014) Kayak Federasyonu Başkanlığı, Alp disiplini ve Kuzey disiplini yarışma pistleri teknik bilgileri.

Ayaz N, Apak ÖC (2016) Kış turizmine katılan yerli ziyaretçilerin seyahat davranışları: Erciyes kayak merkezi örneği. Erciyes Üniversitesi İktisadi ve İdari Bilimler Fakültesi Dergisi, 49,27-43.

Beinat, E. and P. Nijkamp (1998) Multicriteria evaluation for land use management. Dordrecht: Kluwer Academic Publisher.

Berberoglu S (1999) Optimising the remote sensing of Mediterranean land cover. PhD Thesis 205 pp. Faculty of Science, University of Southampton, Southampton, UK.

Carr JR (1996) Spectral and textural classification of single and multiple band digital images, Computers and Geosciences, 22, 849-865. 
Carver S (1991) Integrating multicriteria evaluation with GIS. International Journal of Geographical Information Systems, 5(3):321-339.

Dezsi Ş, Nistor M, Man TC, Rusu R (2015) The GIS assessment of a winter sports resort location. Case study: Belis District, Western Carpathians. Carpathian Journal of Earth and Environmental Sciences 10:223-230.

Düzen B, Şatır O (2016) 6. Uzaktan Algilama-CBS sempozyumu (UZALCBS 2016), 5-7 Ekim 2016, Adana, 972-978.

Eastman JR, McKendry J, Fulk M.A (2005) Change and time series analysis. In:Explorations in Geographic Informations Systems Technology, United Nations Institute for Training and Research (UNITAR), Geneva.

Gençer RT, Demir C, Aycan A (2008) Kayak merkezlerindeki spor turistlerinin hizmet kalitesi algılarını etkileyen değişkenler. Ege Akademik Bakış, 8,437-450.
Gürer I, Özbek T, Gürer N (2004) Determination of Design Criteria for Winter Tourism Area, Gazi University Research Fund, Ankara

Janssen R (1992) Multiobjective decision support for environmental management. Dordrecht: Kluwer Academic.

Miranda FP, MacDonald, Carr JR (1992) Application of the semivariogram textural classifier (STC) for vegetation discrimination using SIR-B data of Borneo. International Journal of Remote Sensing; 13: 2349-2354.

Silberman JA, Rees PW (2010) Reinventing mountain settlements: A GIS model for identifying possible ski towns in the U.S. Rocky Mountains. Applied Geography, 30:36-49.

Topay M, Parladır MÖ (2014) Isparta illi örneğinde CBS yardımıyla alternatif turizm etkinlikleri için yygunluk analizi, Tarım Bilimleri Dergisi, 21,300-309. 